\title{
12 \\ Power Dynamics in Barnahus Collaboration
}

\section{Susanna Johansson}

\section{Introduction}

Varying forms of inter-organisational collaboration in services for vulnerable children have grown rapidly during recent decades and enjoy an almost taken-for-granted status associated with consensus and synergetic decision-making (Horwath and Morrison 2007; Glad 2006; Wiklund 2007). Coercive legislation on collaboration regarding children at risk has also been imposed in Sweden (see, e.g. prop. 2002/03:53), implying increased demands on collaboration within the field. The incapacity of the justice system to meet children's rights as crime victims has, in addition, led to a variety of measures in order to improve children's access to justice and reduce secondary victimisation.

S. Johansson $(\bowtie)$

School of Social Work, Lund University, Lund, Sweden

e-mail: susanna.johansson@soch.lu.se 
These developments have contributed to the establishment of the Barnahus model in Sweden, with the dual goal of a more efficient judicial process on the one hand and improved protection and support on the other hand (see, e.g. Swedish Ministry of Justice 2005).

Collaboration in Swedish Barnahus can be seen as a development towards a more structured form of collaboration between agencies and professional actors from child welfare services, health care and law enforcement in investigations of suspected child abuse. The Barnahus collaboration includes overall collaboration, as well as collaboration in individual cases of child abuse. The agencies involved form a sort of 'hybrid organisation' spanning different regulatory fields and bringing together different institutional logics stemming from social welfare law on the one hand and criminal (procedural) law on the other (Johansson 2011a, 2013). In a Swedish context, there are two parallel investigations that are often coordinated in Barnahus: the child welfare investigation, which the child welfare services are responsible for, and the criminal investigation that is led and conducted by public prosecutors and police investigators. Other professional actors, such as child psychologists, forensic medicine technicians and paediatricians, can also be activated in relation to, or as a consequence of, the child welfare and/or criminal investigations. Police and prosecutor's (pre-trial) criminal investigations are focused on investigating whether a crime has been committed or not, and securing evidence, and are thus directed towards assessments of what has happened in the past, typically characterised by 'ex postoriented' decision-making. The child welfare services investigation, on the other hand, is focused on ensuring the child's protection, welfare and development, which implies assessments of the child's present and future situation, typically characterised by 'ex ante-oriented' decisionmaking. These different decision-making logics may cause tensions in the collaborative practice (Johansson 2011a, b).

Even though collaboration is associated with consensus and synergy, conflicts and dilemmas often arise in collaborative practice. The purpose of this chapter is to analyse collaboration in Swedish Barnahus with a focus on the institutional power dynamics that may develop between the agencies and professional actors involved, and to discuss how the tension between 'justice' and 'welfare' is balanced. 


\section{Theoretical Framework}

The importance and lack of a nuanced power perspective is stressed within organisational research (Clegg et al. 2006). This is also true for studies of inter-organisational collaboration more specifically (Phillips et al. 2000; Hardy and Phillips 1998). This chapter combines the institutional theory of organisations (see, e.g. DiMaggio and Powell 1991; Scott 2008a) with Steven Lukes' (2005 [1974]) three-dimensional power concept in order to facilitate a nuanced analysis of different power dynamics and institutionalisation processes activated in, as well as resulting from, collaboration.

\section{Institutional Theory of Organisations}

Within institutional theory, organisations are seen to be influenced and permeated by the surrounding institutional environment, which also creates interdependencies among organisations within an organisational field. According to Richard Scott (2008a), institutions consist of regulative, normative and cultural-cognitive elements (Scott 2008a, 48), affecting how organisations both think and act. Institutional theory emphasises the symbolic and legitimacy-seeking elements of organisational life and practice, often stressing the isomorphic tendencies among organisations within a field (DiMaggio and Powell 1983). By the end of the 1980s, however, the 'new institutionalism' had started to direct attention to organisations as active agents and not only passive reflections of their institutional environments. It was acknowledged that institutional environments are not homogeneous but rather contested and contradictory, often imposing conflicting demands on organisations. Attention was directed towards power, strategic action and translation processes (Czarniawska and Sevón 1996; Røvik 2000). The concept of institutional logics was defined as interpretative schemas associated with control structures and decision-making systems, or as organising principles, comprising material rules of conduct and symbolic structures, which can be linked to individual organisations in a specific 
context of collaboration (see Friedland and Alford 1991; Thornton and Ocasio 2008; Scott 2008a; Reay and Hinings 2009; Thornton, Ocasio and Lounsbury 2012). When a context of collaboration spans several fields and jurisdictions, such as in Barnahus, the collaborative processes are made more complex (Phillips et al. 2000, 30; Johansson 2013, 116). By viewing the interests of organisations as institutionally shaped, and the organisations as governed by different logics of action, it is possible to understand the conflicts and dilemmas that can arise in interorganisational collaboration and the collaborative work in Barnahus more specifically.

Collaboration in the particular context of Swedish Barnahus is located in an area of contention between two regulatory fields, criminal (procedural) law and social welfare law. In relation to collaboration in Barnahus, the tension between justice and welfare, and more specifically the criminal law-oriented and treatment-oriented logics, is the most central, although there are also 'internal' tensions such as those between the crime victim and the suspect on the one hand, and between child protection and family support on the other hand (Johansson 2011a, b). The parallel investigations (i.e. the criminal and child welfare investigations), related to the criminal and child welfare regulatory fields, represent conflicting institutional interests and logics of decision-making. The Swedish Barnahus collaboration and coordination of the parallel investigations thus require that interests be balanced. This balancing is not undertaken by a single professional actor but through negotiations among the collaborative actors involved. The professional actor's authority and legitimacy are then based on their ability to argue in line with their respective logics, which creates frameworks for handling issues and making decisions that are addressed and negotiated in collaboration (Scott 2008b). ${ }^{1}$

\section{Three Dimensions of Power in Collaboration}

In order to analyse how and why the collaborative actors, as well as their respective institutional logics, affect and are affected by each other in collaboration, a nuanced concept of power is needed. Lukes (2005 
[1974]) concept of power illustrates how power is contextually dependent and takes on different forms. He divides power into three dimensions: one-, two- and three-dimensional power. One-dimensional power relates to concrete action in decision-making on issues where there is an observable conflict of articulated interests, which could be labelled 'formal decision-making power'. According to Lukes, two-dimensional power also enables analysis of how decisions are prevented on issues where there is a conflict of interests. Two-dimensional power thus refers to the extent to which an actor or professional group (consciously or unconsciously) creates or reinforces barriers to conflicts being articulated in public, and the same actor or group possesses power (Lukes 2005, 20), which could be labelled 'non-decision-making power'. According to Lukes, the two-dimensional power view is still too narrow since it does not capture the ways in which latent conflicts are being oppressed (Lukes 2005, 58-59). Lukes therefore includes a three-dimensional power concept to acknowledge elements of power that are not directly visible. According to Lukes, power is at its most effective when least observable, in other words when it operates in disguise or is made invisible (Lukes 2005).

In my understanding, invisible power has to do with conflicting institutional interests being neutralised, avoided or completely concealed. In relation to collaboration, as in Barnahus, such a perspective is important. The idea of collaboration exerts a kind of 'cognitive power' that builds on the idea of consensus, which may conceal underlying conflicts of interests between the organisations involved. Subsequently, the collaborative actors might be unaware of these conflicts, both those exercising power and those upon whom power is exercised. In this way, the third dimension of power addresses 'the power over thought', that is, the capacity to influence actors ways of thinking in a certain direction, or to dominate or redirect their interests. ${ }^{2}$ It is about 'setting the agenda' in a wider cognitive sense by making certain ways of thinking dominant. Three-dimensional power is thus about affecting the preferences of others in a way that makes them accept their role and position in the prevailing institutional order and, in that sense, ensure actors' voluntary compliance to dominance (Lukes 2005). As I interpret Lukes, however, the three-dimensional form of power does not replace the other two, 
but rather implies that power takes place one-, two- and three-dimensionally, and that these dimensions interact. Lukes also stresses that it is important to acknowledge that power in its (more open and visible) one- and two-dimensional forms has several three-dimensional effects (Lukes 2005, 121-122).

Thus open, visible conflict between actors (one-dimensional power) can lead to asymmetric power relations in which those who prevail control the agenda (two-dimensional power) ... are eventually able to count on the compliance of others in the absence of observable conflict of interests (three-dimensional power) (Lukes and Haglund 2005, 62).

In summary, one-dimensional power could be understood as a question of who holds the formal decision-making power over specific issues addressed in the Barnahus collaboration. Two-dimensional power relates to who possesses the power over 'non-decisions', such as which issues should be addressed and not, or who is included and excluded from collaborative arenas. Three-dimensional power relates to who, or rather what, has the power to 'set the agenda' in a broader cognitive sense, for example, when it comes to problem definitions, priority rights of interpretation and affecting (other's) institutional interests (Johansson 2011a). It might very well be that different actors possess different dimensions of power in a specific collaborative context and, in doing so, also affect and change the conditions for each other's abilities to exercise power, and therefore, it becomes important to analyse how the three dimensions of power interact and affect each other in the context of Barnahus collaboration.

\section{Methodology and Empirical Material}

Drawing on my doctoral thesis (Johansson 2011a), this chapter presents a theory-driven re-analysis of empirical material collected within the six first Barnahus in Sweden. The empirical studies comprised interviews with Barnahus staff, a questionnaire survey of the collaborating organisations, and observations of consultation meetings. The interview study 
included interviews with all Barnahus staff at the six Barnahus, amounting to 15 interviews with 22 interviewees, of which nine were carried out individually and six in groups. Apart from four interviewees, all participants in the interview study had social work as professional background and functioned as Barnahus coordinators and/or managers (i.e. not as child welfare caseworkers). The questionnaire survey was sent out to all agency members in the collaborative groups (i.e. steering-, referential- and working groups) and was subsequently directed to professional actors from child welfare services (including child welfare caseworkers), health care (including child psychologists, forensic medicine technicians and paediatricians) and law enforcement (including police investigators and public prosecutors), amounting to 146 respondents, of whom 105 answered the survey (i.e. a response rate of $72 \%$ ). Observations of consultation meetings at each Barnahus were made in connection with carrying out the interviews with the Barnahus staff. ${ }^{3}$

\section{Analysis}

Since both professional training and more specific organisational roles influence the power dynamics developing in the Barnahus collaboration, some clarifications are initially needed as a background to the following analysis. The Barnahus staff at the different Swedish Barnahus are primarily constituted of social workers who are coordinators that summon the different professional actors to 'consultation meetings' and 'co-hearings' for child investigative interviews. ${ }^{4}$ The Barnahus coordinators lead the consultation meetings and make sure that the parallel investigations are coordinated in a suitable way. They often function as advisors for the child welfare caseworkers responsible for the child welfare investigations on matters such as how they should 'go about' the initial stages of the investigation process. The other actors, that is, child welfare caseworkers, police and prosecutors, as well as representatives from health care, generally attend Barnahus temporarily in connection with consultation meetings, co-hearings and/or when making different interventions in relation to either the child welfare or criminal investigations. 


\section{Perceptions of Power (Im)Balance}

In the questionnaire survey sent to all the collaborating agencies, one question was 'Do you consider any agency representatives to possess more influence than others in your collaborative work?' Just over half the respondents stated that there were agencies possessing more influence than others in the Barnahus collaboration, and the child welfare services, police and prosecutors were clearly the three agencies (and professional groups) perceived as most influential, with an even distribution among them.

A first implication of this reply pattern would be to draw the conclusion that there seems to be an asymmetrical power relationship between child welfare services, police and prosecutors on the one hand and representatives from health care (including child psychologists, forensic medicine technicians and paediatricians) on the other hand. This result can be interpreted in relation to what Lukes calls one-dimensional power, or formal decision-making power. In this context, one-dimensional power can be understood as who holds formal decision-making power over the issues addressed in collaboration related to the parallel investigations. On the basis of the child welfare services, police and prosecutors being the agencies and professional actors possessing investigatory responsibility over the child welfare and criminal investigations, respectively, they subsequently hold a structurally based, formal decision-making power over several central and legally defined issues addressed in collaboration, which healthcare actors lack. For example, whether a police report will be filed by the child welfare services, or whether a criminal investigation will proceed and lead to a decision to prosecute.

A second implication would be to draw the conclusion that there seems to be a symmetrical power relationship amongst the representatives from the child welfare services, police and prosecutors, although the public prosecutors significantly less often considered any agency actors to possess more influence than others, compared to the other respondents. At the same time, the prosecutors themselves constitute one of the three agencies and professional groups perceived as 
possessing most influence by the others. In this light, it is important to recognise that the way power balances are distributed, perceived and used is not necessarily consistent. This can be interpreted in relation to Lukes' notion of power as being exercised both consciously and unconsciously. For example, you can be unconscious of how others perceive your actions, which in this case might explain the prosecutors' deviant reply pattern. In the same way, you can be conscious or unconscious of the consequences of your actions, and the 'real' intentions behind or the 'real' meaning of your actions.

The question addressed in the questionnaire survey was formulated in a way that is open to a broader interpretation. When agencies are considered to possess more influence than others in collaboration, it is not necessarily (only) connected to one-dimensional decision-making power. It can (also) relate to the actors that are considered to possess more influence than others concerning, for example, who is included in or excluded from collaboration, which issues to be addressed or not during consultation meetings or who has more influence than others over problem definitions. In other words, this could be interpreted as twoand three-dimensional power.

\section{'Setting the Agenda' by Including and Excluding Actors from Collaborative Arenas}

In relation to the permeating tension between the criminal law-oriented logic and the treatment-oriented logic, collaboration in Barnahus can be understood as characterised by competitions in 'framing' or 'setting' the agenda. In the questionnaire survey, for example, in response to the open question of what are considered to be the main difficulties with the collaboration, one respondent (forensic medicine) answered that there were ' $(. .$.$) different agendas among the agencies regarding what$ is of highest importance-the criminal investigation, the family or the child's mental well-being'.

An important issue when it comes to setting the agenda for the Barnahus collaboration turned out to be inclusions and exclusions of 
collaborative actors in relation to consultation meetings and co-hearings of child investigative interviews. The analysis of the empirical material shows variations between the different Barnahus regarding how these collaborative arenas were organised, which organisations were included and excluded from the arenas and, in turn, what content (related to which logics) the collaboration involved. Participation can thus be seen as a basic circumstance for the ability to exercise influence and power over different issues during a consultation meeting or in relation to cohearings of child investigative interviews. At the same time, participation also implies the potential to be influenced and affected by others (and their institutional logics).

\section{Consultation Meetings}

Partly as a consequence of varied interpretations of rules of secrecy, the content of consultation meetings differed between the different Barnahus. For example, some Barnahus held consultation meetings between the child welfare services, police and prosecutors on the issue of whether a police report should be filed or not, while other Barnahus didn't hold consultation meetings with police and prosecutors attending until a police report had formally been filed from the child welfare service. In the latter case, consultation meetings were sometimes, instead, initially held between the child welfare services and child psychologists on partly different matters. The formal decision-making power over the question of police reports can, in this respect, be interpreted as being kept within the child welfare service's own organisation. These differences reflect variations regarding which collaborative actors were included or excluded from initial consultation meetings and how this, in turn, framed the issues that were addressed in the collaboration and the decisions made during, or in relation to, collaboration.

At those Barnahus where consultation meetings primarily considered the question of whether a police report should be filed or not, all agencies were included. In this case, the child welfare caseworker's formal authority and decision-making power over the question of filing police reports were affected by several collaborative actors. Both police 
and prosecutors, and the Barnahus coordinators leading the consultation meetings, were in this case regarded as specialists. They thus possessed a more diffuse two- and three-dimensional power over central issues related to the child welfare investigations, such as the question of police reports and the initial stages of the child welfare investigation process. At those Barnahus where consultation meetings were not related to the question of police reports, the collaboration rather revolved around questions such as in which order the different agency interventions should be made. Here, some respondents also had the ability to influence police and prosecutor criminal investigations by putting forward arguments about the importance of speeding up the judicial process from the perspective of the child's well-being and in relation to treatment and support interventions. Several police investigators also described how they, through the increased collaboration, had more opportunities to affect the prosecutor's decisions on whether a criminal investigation should proceed and lead to a decision to prosecute.

\section{Co-hearings of (Forensic) Child Investigative Interviews}

Variations were also identified between the different Barnahus regarding the organisation of 'co-hearings' of the child investigative interviews (taking place in an adjacent monitor room next to the interview room). Similar to the consultation meetings, these variations were partly connected to varied interpretations of rules of secrecy. Here, it was not the Barnahus coordinators who primarily decided which actors to include or exclude, even though it was the coordinators who in fact summoned the collaborative actors in both cases, but instead the public prosecutors who had investigatory responsibility and one-dimensional decision-making power over the criminal investigations that decided which actors were allowed to participate and not. At some Barnahus, all agencies and professional actors were included in the co-hearings of the child investigative interviews, while at others only some, or even none, of the collaborative actors were included.

In cases where the collaborative actors were allowed to participate in the co-hearings of the child investigative interviews, there were still 
other differences. Variations in the organisation of co-hearings can, then, be interpreted as the purpose of the co-hearing being sometimes related to the criminal law-oriented logic and at other times to the treatment-oriented logic. Consequently, the different collaborative actors possess different roles as institutional agents in relation to the co-hearings, sometimes related to the criminal law-oriented logic and other times to the treatment-oriented logic. For example, in some cases the purpose of the co-hearings was to constitute support for the criminal investigations, for example, when the police investigators consulted child psychologists about interpretations of the children's statements and expressions. In other cases, the purpose was to constitute support for the child welfare investigations, for example, when child welfare caseworkers used the information disclosed during child investigative interviews in their risk assessments.

At some Barnahus, neither the Barnahus coordinators nor the child welfare caseworkers were allowed to participate in the co-hearings due to the interpretations of the secrecy rules of the criminal investigations, as illustrated in this interview sequence with two Barnahus staff:

Interviewer: These child investigative interviews that are being video recorded, are you also there and watching [in the adjacent monitor room for co-hearings]? Interviewees A and B: No. Interviewer: It's the police by themselves? Interviewee B: Yes, and the child's representative, and perhaps the prosecutor in some cases. So, we get as much information about the investigative interviews as the police and prosecutor decide to disclose. (Barnahus staff)

Viewed in this light, the prosecutor's one-dimensional power (related to the criminal investigations) can be interpreted as leading to an asymmetric power relationship where they (also) dominate control over the agenda concerning participation in the co-hearings (i.e. two-dimensional power), which, in turn, might lead to three-dimensional power effects.

The inclusions and exclusion of collaborative actors from the cohearings of child investigative interviews and consultation meetings can be understood as a matter of controlling access to information and, 
subsequently, either enabling or preventing action from other collaborative actors in relation to their respective institutional interests and logics (based on this non/information).

\section{Coordinator Influence on Formal Decision-Making Power}

When it comes to the influence of the child welfare services, an important difference between the Barnahus staff functioning as coordinators at the Barnahus on the one hand and the child welfare caseworkers responsible for the child welfare investigations on the other hand is crystallised. Even though both are usually social workers and employed within the child welfare services, they exercise different forms of power based on which roles they possess in the Barnahus collaboration. The investigatory child welfare caseworkers possess a one-dimensional form of power and thus a formal authority, over central issues and decisions related to the child welfare investigations, while the Barnahus coordinators possess a more diffuse two- and three-dimensional power over the collaborative processes and over the child welfare caseworkers.

It is interesting to note that the social workers functioning as coordinators at the different Barnahus noted on several occasions that they do not possess any investigatory responsibility or decision-making power:

Although, I have absolutely no investigatory responsibility, rather we can assist the child welfare services in some parts (...). (Barnahus coordinator)

While it was important for Barnahus coordinators to stress this, it was also noted as a complicating factor in relation to establishing collaboration:

All agencies decide about themselves, so to speak. Yet, what is difficult (...) about collaboration is that nobody has an overall responsibility to go in and say to the prosecutor that this is what you have to do, or tell the police that you have to do like this, or to the child welfare services that you need to do this. That's what's difficult with collaboration. No one is mandated to decide for all agencies. (Barnahus coordinator) 
By possessing roles as coordinators and functioning as specialised advisors primarily for the child welfare caseworkers (e.g. in matters such as decisions on filing police reports and other central issues related to the child welfare investigations), the Barnahus coordinators can be seen as exercising both two- and three-dimensional powers. These power forms can influence, affect and change the conditions of the one-dimensional decision-making power (and formal authority) of the child welfare caseworkers through consciously or unconsciously becoming dominated. For example, one coordinator at a Barnahus explained that:

The most common situation is that the child welfare services call [the Barnahus], having received a report of suspected abuse. And after a short conversation over the telephone you decide quite quickly whether they should come here and present it to the police and prosecutor as well. And the psychologist. In consultation, that is. The biggest cases are handled in consultation [meetings] in order for everyone to have a say, to [express] their opinion. And then you do so. Sometimes things come up in the meantime so to speak, but the most common issues are: Should we file a police report in this case? How should we go about this? What do we need? They [the child welfare case workers] are often a bit worried about how serious it is, and so on, and which way they should go about in the case. And then, we sit gathered around the table and make these assessments. Police report and send it there and there, do this and that, write here and there. And take these and these contacts as part of the investigation process. After that, we await the police report and eventual child investigative interviews. If there is a queue, you might have to advise them [the child welfare case workers] to place [the child] and help them with the arrangement for that, then (Barnahus coordinator).

The analysis furthermore shows that this power, exercised by the Barnahus coordinators upon the child welfare caseworkers, in turn, is influenced by the police and prosecutor's criminal law-oriented logic, and the demands from police and prosecutors in relation to this logic.

In accordance with the secrecy rules of the criminal investigations, we propose to the child welfare services that we do not want them to inform 
the custodians about a police report until investigative interviews with the children have been carried out (Barnahus coordinator).

These arguments and requests directed towards the child welfare caseworkers may impact and change how the caseworkers make assessments and decisions in relation to the child welfare investigations. For example, in the questionnaire survey, one child welfare caseworker described how the Barnahus collaboration had changed the working methods of the child welfare services:

To a larger extent, you try to avoid informing the custodians (if they are suspected perpetrators) directly 1) that a child welfare investigation according to 11:1, 2 SoL [The Social Services Act] is initiated, 2) that a police report on suspected crime against the child will be/has been filed, and you, to a larger extent, are more concerned about having direct collaboration with [the Barnahus], police and prosecutor. (Child welfare caseworker)

As shown above, the Barnahus staff with specific roles as coordinators are powerful actors in the Barnahus collaboration. They can be interpreted as possessing strong influence and control over the collaborative processes and the decisions made (and not made), during collaboration, even though they (structurally viewed) lack one-dimensional decisionmaking power and formal authority in relation to the parallel investigations. For example, they determine which cases to hold consultation meetings around and which collaborative actors should be summoned. Other forms of power (which can be one-, two- and three-dimensional), exercised by other collaborative actors, can simultaneously influence and affect the coordinators' circumstances of exercising power.

The collaborative actors thus hold different positions and forms of power in collaboration 'from the start', due to the institutional structures that the specific collaboration is embedded within. At the same time, these positions are re-negotiated and changed to different degrees due to the more action-oriented power dynamics activated in collaboration. Prosecutors and child welfare caseworkers possess clear and 
visible one-dimensional decision-making power related to the parallel investigations; however, other more diffuse and partly invisible power dimensions can influence and affect these positions, with several threedimensional power effects from the broader institutionalisation processes resulting from the Barnahus collaboration.

\section{Juridification as a Three-Dimensional Power Effect}

In a generalised sense, the analysis has shown how criminal law-oriented logic (focused on 'justice' and targeting a more efficient and improved judicial process) has gained priority at the expense of treatmentoriented logic (focused on 'welfare' and targeting improved and childadapted protection and support). Expressed differently, the tension between 'justice' and 'welfare' has resulted in an unequal power balance between the agencies and their associated investigations and interventions. This change in power balance constitutes the process that I have called juridification (see Johansson 2011a, b). Juridification then is a process where the professional actors who are related to the treatmentoriented logic are letting themselves be influenced by, and adapts their working methods to, the criminal law-oriented logic. I interpret this as an institutional change resulting from the Barnahus collaboration.

The process of juridification was, among other things, reflected in how work assessments and interventions were prioritised, that is, in which sequence different interventions related to the child welfare and criminal investigations were conducted. Several child welfare caseworkers described how the Barnahus collaboration had resulted in them adjusting to police and prosecutor wishes to conduct their investigatory interventions before the child welfare services contacted custodians and informed them about the child welfare investigation. They described how this change affected and indeed complicated the initial and continuous contact and motivation work with the family, including accessing consent for support and treatment interventions for the children. 
For example, one interviewee from the Barnahus staff explained the need for including, motivating and getting the family along in relation to the child welfare investigation process and the difficulties here of related to the judicial process:

The goal is to - as quickly as possible after this disclosure - get in contact with the family. It is the nature of a case like this that it is difficult to make contact with the family. Most of the time it is someone in the family that is suspected of abusing the child. That is shameful, and many times when a police report has been filed they deny it. How are they supposed to admit to us that they hit their children, when it means admitting it to the police at the same time. It is very difficult to get this contact with the parents and the child. In order to get the child here [for support or treatment], we need to go through the parents. (Barnahus staff)

Another respondent from the survey stated that:

The collaborative work has now a very clear focus on the judicial process. However, the child's/family's need for support, crisis counselling and so on has been pushed further into the background than what I had hoped for. (Child psychologist)

Even if some actors seemed aware, and to some extent even sceptical, about the stronger focus on the judicial process and adaption to the criminal law-oriented logic, the child welfare service representatives still accepted this way of thinking (and acting), as well as their roles and positions in the institutional order under making. In the questionnaire survey, child welfare services reported that they had changed their working methods the most as a consequence of the Barnahus collaboration; however, it is important to note, in relation to the criminal law-oriented logic rather than the treatment-oriented logic, what could be described as an 'adoption' of a contradictory institutional logic. 


\section{Conclusion}

The analysis presented in this chapter, contextually based on the six first Barnahus in Sweden, has shown how Barnahus coordinators can be seen as exercising two- and three-dimensional power, partly over the organisation of the collaborative practices within Barnahus (such as consultation meetings) and partly over the child welfare caseworkers in relation to how they should 'go about' the child welfare investigations. On the other hand, the coordinators themselves are subjected to three-dimensional power in the sense of being 'carriers' of the police and prosecutor's institutional interests rather than interests stemming from a treatment-oriented logic. In that sense, they can be interpreted as being dominated by the criminal law-oriented logic and, in turn, argue on the basis of this logic when influencing the child welfare caseworkers about matters connected to the child welfare investigations.

Juridification can be understood as a move towards a new institutional power order, which includes a modification in power balance between the treatment-oriented and the criminal law-oriented logics, implying a content-wise focus on justice rather than welfare. More concretely, this implies a primary focus on the suspected crimes rather than investigating how the future situations of children and families can be improved by support and treatment interventions.

Juridification can be understood as an on-going institutionalisation process, wherein this Barnahus setting, and the different agencies and actors involved in this collaboration, have come to develop increasingly towards a common field (cf. Stefansen et al. Chap. 16). Juridification can be interpreted as a three-dimensional power effect, as an institutionally tied exercise of power, which might increasingly come to be taken-for-granted as something 'natural': in other words become institutionalised. By seeing collaboration as something undergoing constant negotiation and change, however, this power (im)balance does not have to be seen as static, since it might be re-activated and re-negotiated and, in turn, lead to a new power balance and institutional order in the field of tension between justice and welfare. The balance between justice and 
welfare could, subsequently, be of different character; conflicting, contested, dominated or - perhaps- equally balanced.

\section{Notes}

1. According to Scott (2008b) some professionals, understood as institutional agents, primarily possess formal authority (e.g. based on regulative power), others normative authority (e.g. based on normative principles of 'how to act') and yet others cultural-cognitive authority (e.g. based on knowledge claims and competence).

2. Cf. Stein Bråten on 'model power' and 'model monopoly' (Bråten 1973).

3. For a more detailed description of the methodological approach and empirical materials, see Johansson (2011a). The study was approved by the Regional Ethical Review Board in Lund. In the analysis section, all quotes from the empirical material are translated from Swedish into English by the author.

4. At some Swedish Barnahus, however, also psychologists and/or police investigators work as Barnahus staff (cf. Johansson et al. chap. 1).

Acknowledgements I would like to thank my co-editors Elisiv Bakketeig, Kari Stefansen and Anna Kaldal for valuable discussions and improving comments in the process of finalizing this chapter.

\section{References}

Bråten, Stein. 1973. Model Monopoly and Communication: Systems Theoretical Notes on Democratization. Acta Sociologica 16 (2): 98-107.

Clegg, Stewart, David Courpasson, and Nelson Phillips. 2006. Power and Organizations. London: Sage Publications.

Czarniawska, Barbara, and Guje Sevón (eds.). 1996. Translating Organizational Change. New York: Walter de Gruyter.

DiMaggio, Paul J., and Walter W. Powell. 1983. The Iron Cage Revisited: Institutional Isomorphism and Collective Rationality in Organizational Fields. American Sociological Review 48 (2): 147-160.

DiMaggio, Paul J., and Walter W. Powell (eds.). 1991. The New Institutionalism in Organizational Analysis. London: The University of Chicago Press. 
Friedland, Roger, and Robert R. Alford. 1991. "Bringing Society Back. In: Symbols, Practices, and Institutional Contradictions." In The New Institutionalism in Organizational Analysis, eds. Paul J. DiMaggio, and Walter W. Powell, 232-263. London: The University of Chicago Press.

Glad, Johan. 2006. Co-operation in a Child Welfare Case: A Comparative Cross-national Vignette Study. European Journal of Social Work 9 (2): 223-240.

Hardy, Cynthia, and Nelson Phillips. 1998. Strategies of Engagement: Lessons from the Critical Examination of Collaboration and Conflict in an Interorganizational Domain. Organization Science 9 (2): 217-230.

Horwath, Jan, and Tony Morrison. 2007. Collaboration, Integration and Change in Children's Services: Critical Issues and Key Ingredients. Child Abuse and Neglect 31(1): 55-69.

Johansson, Susanna. 2011a. Rätt, makt och institutionell förändring. En kritisk analys av myndigheters samverkan i barnahus. Lund Studies in Sociology of Law 35: Lund University.

Johansson, Susanna. 2011b. Juridifiering som institutionell förändring. Om mötet mellan straffrätt och socialrätt vid interorganisatorisk samverkan. Retfærd. Nordic Journal of Law and Justice 34/135: 38-59.

Johansson, Susanna. 2013. Institutions and Norms in Collaboration: Towards a Framework for Analysing Law and Normativity in Inter-organizational Collaboration. In Social and Legal Norms, ed. Matthias Baier, 107-120. Aldershot: Ashgate Publishing.

Lukes, Steven. 1974. Power: A Radical View. Basingstoke: Palgrave Macmillan. Lukes, Steven. 2005. Power: A Radical View. The original text with two major new chapters. Basingstoke: Palgrave Macmillan.

Lukes, Steven, and Ladawn Haglund. 2005. Power and Luck. Archives européennes de sociologie 46(1): 45-66.

Phillips, Nelson, Thomas Lawrence, and Cynthia Hardy. 2000. InterOrganizational Collaboration and the Dynamics of Institutional Fields. Journal of Management Studies 37 (1): 23-43.

Proposition 2002/03:53 Stärkt skydd för barn i utsatta situationer. Stockholm: Government bill.

Reay, Trish, and C.R. Hinings. 2009. Managing the Rivalry of Competing Institutional Logics. Organization Studies 30 (6): 629-652.

Røvik, Kjell Arne. 2000. Moderna organisationer: trender inom organisationstänkandet vid millennieskiftet. Malmö: Liber.

Scott, Richard W. 2008a. Institutions and Organizations. Ideas and Interests. London: Sage Publications. 
Scott, Richard W. 2008b. Lords of the Dance: Professionals as Institutional Agents. Organization Studies 29: 219-238.

Swedish Ministry of Justice. 2005. Regeringsbeslut. Uppdrag att medverka till etablering av flera försöksverksamheter med samverkan under gemensamt tak vid utredningar kring barn som misstänks vara utsatta för allvarliga brott. Stockholm: Ministry of Justice.

Thornton, Patricia H. and William Ocasio. 2008."Institutional Logics." In The SAGE Handbook of Organizational Institutionalism, eds. Royston Greenwood, Christine Oliver, Kerstin Sahlin-Andersson and Roy Suddaby. London: Sage Publications.

Thornton, Patricia H., William Ocasio, and Michael Lounsbury. 2012. The Institutional Logics Perspective. A New Approach to Culture, Structure, and Process. New York: Oxford University Press.

Wiklund, Stefan. 2007. United we stand? Collaboration as a means for identifying children and adolescents at risk. International Journal of Social Welfare 16: $202-211$.

Open Access This chapter is licensed under the terms of the Creative Commons Attribution 4.0 International License (http://creativecommons. org/licenses/by/4.0/), which permits use, sharing, adaptation, distribution and reproduction in any medium or format, as long as you give appropriate credit to the original author(s) and the source, provide a link to the Creative Commons license and indicate if changes were made.

The images or other third party material in this chapter are included in the chapter's Creative Commons license, unless indicated otherwise in a credit line to the material. If material is not included in the chapter's Creative Commons license and your intended use is not permitted by statutory regulation or exceeds the permitted use, you will need to obtain permission directly from the copyright holder.

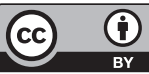

